\title{
AMELOGÊNESE IMPERFEITA EM PACIENTES INFANTIS: ORIGENS, CARACTERÍSTICAS E POSSÍVEIS TRATAMENTOS - REVISÃO DE LITERATURA
}

\author{
Paola da Silva1', Franciele Dias', Cristiane Medianeira Savian², Cândida \\ Bonadiman Jung ${ }^{3}$, Letícia Westphalen Bento ${ }^{4}$, Simone Pippi Antoniazzi ${ }^{4}$, \\ Maurício Barbieri Mezomo ${ }^{4}$, Bianca Zimmermann Santos ${ }^{5}$
}

\section{RESUMO}

O objetivo desta revisão de literatura é descrever as origens, características e possíveis tratamentos da amelogênese imperfeita em crianças. As buscas foram realizadas nas bases MEDLINE/PubMed e BVS. Na base MEDLINE/PubMed foram considerados os descritores do MeSH: "Tooth demineralization" AND "child". Na BVS foram utilizados os descritores do DeCS: "Desmineralização do dente" E "criança". A amelogênese imperfeita é uma condição genética que afeta a formação do esmalte dentário, causando fraturas, exposição da dentina e hipersensibilidade dentinária. $\mathrm{O}$ esmalte dentário é o tecido inorgânico mais forte do corpo humano, protegendo os tecidos dentários das forças mastigatórias. Foram encontrados quatro tipos de amelogênese imperfeita com 15 subgrupos, fazendo com que o correto diagnóstico seja imprescindível no seu tratamento, sempre visando o melhor manejo possível, de forma pouco invasiva e que possa melhorar a funcionalidade dessa dentição, e consequentemente a autoestima dos pacientes.

\footnotetext{
${ }^{1}$ Acadêmica do Curso de Odontologia - UFN - paolams98@hotmail.com

1 Acadêmica do Curso de Odontologia - UFN - frandiasodonto@gmail.com

2Mestre em Saúde Materno Infantil - UFN - cristiane.savian@ufn.edu.br

3Mestranda em Saúde Materno Infantil - UFN - candidabonadiman@ufn.edu.br

${ }^{4}$ Professora do Curso de Odontologia - UFN - Iwbento@ufn.edu.br

4 Professora do Curso de Odontologia - UFN - simonepippi@ufn.edu.br

${ }^{4}$ Professor do Curso de Odontologia - UFN - mauriciomezomo@gmail.com

5Orientadora - Professora do Curso de Odontologia - UFN_biancazsantos@ufn.edu.br
} 
PALAVRAS-CHAVE: amelogênese imperfeita, desmineralização, esmalte dentário, criança.

EIXO TEMÁTICO: Atenção Integral e Promoção à Saúde - AIPS

\section{INTRODUÇÃO}

A Amelogênese Imperfeita (Al) é uma condição hereditária de baixa prevalência, caracterizada como uma má formação do esmalte dentário, causando lascas de esmalte, falta dele e exposição severa de dentina, deixando o dente quebradiço e com hipersensibilidade. A maioria dos casos de Al acontecem devido a mutações de genes que codificam proteínas da matriz do esmalte, estas governam a função crítica durante a iniciação, alongamento e organização mineral do esmalte. (KIM et al., 2017). O fenótipo apresentado quando há amelogênese imperfeita depende do gene afetado, a localização deste, seu tipo de mutação e, consequentemente, a proteína afetada (SANTOS et al., 2005).

O esmalte dentário é o tecido mais mineralizado do corpo humano quando tem sua formação completa, ele recobre a dentina e protege os tecidos dentários das forças mastigatórias. O esmalte normal é sintetizado durante o desenvolvimento do dente como uma matriz extracelular em um processo chamada de amelogênese, que ocorre em dois estágios. No estágio de secreção, o ameloblasto produz uma matriz de proteína mineralizada, esta corresponderá ao esmalte adulto (ALDRED, 2003). Já na fase de maturação, a proteína da matriz é degradada e então, a mineralização está concluída (CRAWFORD, 2007).

A Al pode ser classificada por quatro tipos diferentes, de acordo com suas características, sendo eles: hipoplásico, hipocalcificado, hipoplásico-hipomaturado e hipomaturado-hipoplásico. São hipomaturados quando ocorrem no período de

\footnotetext{
1Acadêmica do Curso de Odontologia - UFN - paolams98@hotmail.com

${ }^{1}$ Acadêmica do Curso de Odontologia - UFN - frandiasodonto@gmail.com

2Mestre em Saúde Materno Infantil - UFN - cristiane.savian@ufn.edu.br

3Mestranda em Saúde Materno Infantil - UFN - candidabonadiman@ufn.edu.br

${ }^{4}$ Professora do Curso de Odontologia - UFN - Iwbento@ufn.edu.br

${ }^{4}$ Professora do Curso de Odontologia - UFN - simonepippi@ufn.edu.br

${ }^{4}$ Professor do Curso de Odontologia - UFN - mauriciomezomo@gmail.com

5Orientadora - Professora do Curso de Odontologia - UFN — biancazsantos@ufn.edu.br
} 
maturação; quando ocorrem na fase de mineralização do esmalte são hipocalcificadas; as hipoplásicas se apresentam nas formas clínicas de depressão localizada, leve difusa e agenesia total do esmalte, ela causa defeito na espessura do esmalte, visto que há defeito na formação da matriz do esmalte e são hipomineralizadas quando há esmalte mineralizado insuficiente, fazendo com que este sofra mais os desgastes abrasivos. Há no mínimo 14 subtipos diferentes de Al hereditárias, com vários padrões de herança e inúmeras manifestações clínicas (NEVILLE et al., 2004). Uma vez que apresenta algumas variações na textura e consistência do esmalte dentário, a identifição da amelogênese imperfeita é feita principalmente pelo exame clínico, mas as características radiográficas certificam a impressão clínica (PHAROAH, 2004). Sendo assim, se faz necessária uma abordagem multidisciplinar visando: avaliar, diagnosticar e resolver os problemas estéticos, usando a combinação de tratamentos periodontais, protéticos, cirúrgicos e restauradores (CRAWFORD et al., 2007).

Neste contexto, o objetivo desta revisão de literatura é descrever as origens, características e possíveis tratamentos da amelogênese imperfeita em crianças.

\section{METODOLOGIA}

O estudo trata de uma revisão de literatura e para o desenvolvimento desta, foi realizada uma busca de artigos referentes ao tema estudado, nas bases de dados MEDLINE/PubMed e BVS (Biblioteca Virtual em Saúde). A pesquisa foi realizada no mês de julho de 2021. Foram utilizados os seguintes descritores do MeSH: "Tooth demineralization" AND "child". Na BVS foram utilizados os descritores do DeCS: “desmineralização dentária” E "criança”. Não foi realizada a delimitação temporal visando obter todos os trabalhos já desenvolvidos sobre o assunto na base de dados citada.

\footnotetext{
${ }^{1}$ Acadêmica do Curso de Odontologia - UFN - paolams98@hotmail.com

1 Acadêmica do Curso de Odontologia - UFN - frandiasodonto@gmail.com

2Mestre em Saúde Materno Infantil - UFN - cristiane.savian@ufn.edu.br

3Mestranda em Saúde Materno Infantil - UFN - candidabonadiman@ufn.edu.br

${ }^{4}$ Professora do Curso de Odontologia - UFN - Iwbento@ufn.edu.br

4 Professora do Curso de Odontologia - UFN - simonepippi@ufn.edu.br

${ }^{4}$ Professor do Curso de Odontologia - UFN - mauriciomezomo@gmail.com

5Orientadora - Professora do Curso de Odontologia - UFN_biancazsantos@ufn.edu.br
} 
Foi realizada a leitura dos títulos e resumos de todos os artigos encontrados, para adequada inclusão dos trabalhos relacionados ao tema. Como critério de inclusão foi considerado: artigos que contemplassem a temática proposta, publicados em português, inglês e espanhol. O critério de exclusão estabelecido foi artigos que não estivessem com o texto completo disponível.

\section{RESULTADOS E DISCUSSÃO}

Por ter classificações complexas, os quatro grupos e seus 15 subgrupos são baseados nos seus tipos de transmissão e nos fenótipos que tenham vindo a causar a má formação do esmalte dentário. De acordo com WITKOP, 1971 estas são as classificações e caracterizações dos diferentes tipos de Al:

Tipo 1 - hipoplásica

a) esmalte fissurado (autossômica dominante-AD)

b) hipoplásica localizada (autossômica dominante-AD)

c) hipoplásica localizada grave (autossômica recessiva-AR)

d) hipoplásica com esmalte de superfície lisa (autossômica dominante-AD)

e) hipoplásica com esmalte liso ligado ao cromossomo X (DLX)

f) hipoplásica com esmalte rugoso (autossômica dominante-AD)

g) agenesia do esmalte (autossômica recessiva-AR) 11

\section{Tipo 2 -hipomaturada}

a) pigmentada (autossômica recessiva-AR)

b) pigmentada (recessiva ligada ao cromossomo $X-R L X)$

c) dente com manchas opacas tipo flocos de neve (hipótese de $\mathrm{RLX})$

1Acadêmica do Curso de Odontologia - UFN - paolams98@hotmail.com

${ }^{1}$ Acadêmica do Curso de Odontologia - UFN - frandiasodonto@gmail.com

2Mestre em Saúde Materno Infantil - UFN - cristiane.savian@ufn.edu.br

3Mestranda em Saúde Materno Infantil - UFN - candidabonadiman@ufn.edu.br

${ }^{4}$ Professora do Curso de Odontologia - UFN - Iwbento@ufn.edu.br

${ }^{4}$ Professora do Curso de Odontologia - UFN - simonepippi@ufn.edu.br

${ }^{4}$ Professor do Curso de Odontologia - UFN - mauriciomezomo@gmail.com

5Orientadora - Professora do Curso de Odontologia - UFN — biancazsantos@ufn.edu.br 
d) dente com manchas opacas tipo flocos de neve (AD)

\section{Tipo 3-hipocalcificada}
a) transmissão dominante (autossômica dominante-AD)
b) transmissão recessiva (autossômica recessiva-AR)

Tipo 4-hipoplásica e por hipomaturação com taurodontia

a) hipomaturação (autossômica dominante-AD)

b) hipoplásica (autossômica dominante-AD)

$\mathrm{Na}$ Al do tipo hipoplásica o esmalte é fino, com presença de fissuras e sulcos, densidade normal e o tamanho do dente é reduzido, levando à falta de contatos proximais entre os dentes. A Al hipomaturada apresenta um esmalte que se solta facilmente da dentina em forma de lascas. Por sua vez, na Al hipocalcificada o esmalte está corretamente depositado, mas não mineralizado, fazendo com que se descole facilmente da dentina, se apresenta nas cores marrom amarelado e alaranjado, com o tempo ele acaba por permanecer apenas na região cervical, onde ocorre uma melhor mineralização, estes dentes, porém, possuem forma e tamanho normais. Já na Al hipoplásica e por hipomaturação com taurodontia há uma combinação da hipoplasia com a hipomaturação do esmalte, atingindo de forma igual as duas dentições do paciente. No entanto, este sistema classificatório proposto é impraticável para a maioria dos clínicos, pois estes devem continuar contando com fenótipo e genótipo para aconselhar pacientes acometidos por Al, levando em conta as implicações genéticas de seus problemas (NEVILLE et al., 2004). A principal herança genética mostrou-se ser a autossômica dominante em grande parte dos casos, ainda que a Al apresente diferentes mutações nos genes responsáveis pela

\footnotetext{
${ }^{1}$ Acadêmica do Curso de Odontologia - UFN - paolams98@hotmail.com

1 Acadêmica do Curso de Odontologia - UFN - frandiasodonto@gmail.com

2Mestre em Saúde Materno Infantil - UFN - cristiane.savian@ufn.edu.br

3Mestranda em Saúde Materno Infantil - UFN - candidabonadiman@ufn.edu.br

${ }^{4}$ Professora do Curso de Odontologia - UFN - Iwbento@ufn.edu.br

4 Professora do Curso de Odontologia - UFN - simonepippi@ufn.edu.br

${ }^{4}$ Professor do Curso de Odontologia - UFN - mauriciomezomo@gmail.com

5Orientadora - Professora do Curso de Odontologia - UFN_biancazsantos@ufn.edu.br
} 
transcrição das proteínas da matriz orgânica do esmalte, levando a uma grande diversidade dos fenótipos da amelogênese imperfeita" (SANTOS et al., 2005).

A reabilitação de pacientes com Al deve levar em consideração suas condições financeiras, visto que será necessário um trabalho multidisciplinar para atenuar as consequências da falta do esmalte sadio na estruturação dentária, sendo necessário o uso de aparelho ortodôntico não fixado em estrutura dentária, cirurgias periodontais, implantes, próteses fixas e materiais restauradores, levando em conta a sobrevida diminuída de materiais adesivos em estruturas dentinárias (GOKCE K. et al., 2007).

Tabela 1: é possível observar os resultados dos estudos de casos-controles e relatos de casos utilizados para a realização desta revisão de literatura.

\begin{tabular}{|c|c|c|c|}
\hline AUTOR & $\begin{array}{l}\text { NÚMERO DE } \\
\text { INDIVIIDUOS }\end{array}$ & TIPO DE AI & TRATAMENTO INDICADO \\
\hline $\begin{array}{l}\text { ADORNO- } \\
\text { FARIAS et al., } \\
2019\end{array}$ & $\begin{array}{l}121 \text { provindos de } \\
41 \text { famílias }\end{array}$ & $\begin{array}{l}\text { - } 72 \text { pacientes afetados } \\
\text { eram IA hipomaturos } \\
(43 \%) \\
\text { - Al hipoplásico (25\%) } \\
\text { - IA hipomaturo / } \\
\text { hipoplásico (21\%) } \\
\text { - IA hipocalcificado } 7 \% \\
\text { - Al hipocalcificado / } \\
\text { hipoplásico } 4 \%\end{array}$ & $\begin{array}{l}\text { Preventivo e restaurador em } \\
\text { trabalho multidisciplinar }\end{array}$ \\
\hline $\begin{array}{l}\text { QUANDALLE } \\
\text { et al., } 2020\end{array}$ & $\begin{array}{l}42 \text { casos para } 42 \\
\text { controles }\end{array}$ & $\begin{array}{l}\text { - hipomaturo (14) } \\
\text { - hipocalcificado (14) } \\
\text { - hipoplásico (14) }\end{array}$ & $\begin{array}{l}\text { - Necessidade maior de } \\
\text { tratamento periodontal } \\
\text { entre os casos, visto maior } \\
\text { percentual de gengivite e } \\
\text { placa visível. }\end{array}$ \\
\hline
\end{tabular}

${ }^{1}$ Acadêmica do Curso de Odontologia - UFN - paolams98@hotmail.com

${ }^{1}$ Acadêmica do Curso de Odontologia - UFN - frandiasodonto@gmail.com

2Mestre em Saúde Materno Infantil - UFN - cristiane.savian@ufn.edu.br

3Mestranda em Saúde Materno Infantil - UFN - candidabonadiman@ufn.edu.br

${ }^{4}$ Professora do Curso de Odontologia - UFN - Iwbento@ufn.edu.br

${ }^{4}$ Professora do Curso de Odontologia - UFN - simonepippi@ufn.edu.br

${ }^{4}$ Professor do Curso de Odontologia - UFN - mauriciomezomo@gmail.com

5Orientadora - Professora do Curso de Odontologia - UFN — biancazsantos@ufn.edu.br 


\begin{tabular}{|c|c|c|c|}
\hline \multicolumn{2}{|c|}{$\begin{array}{l}\text { EDUCAÇÃO, SAÚDE } \\
\text { E TECNOLOGIA } \\
26 \text { A } 28 \text { DE OUTUBRO DE } 2021\end{array}$} & 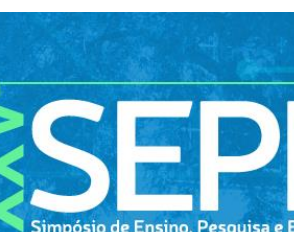 & $\begin{array}{r}\begin{array}{r}\text { ISSN: } 2316-9745 \\
\text { TRABALHO COMPLETO }\end{array} \\
\text { Universidade Franciscana }\end{array}$ \\
\hline $\begin{array}{l}\text { ORTIZ et al., } \\
2019\end{array}$ & $\begin{array}{l}\text { Uma paciente de } \\
16 \text { anos }\end{array}$ & IA hipomaturo & 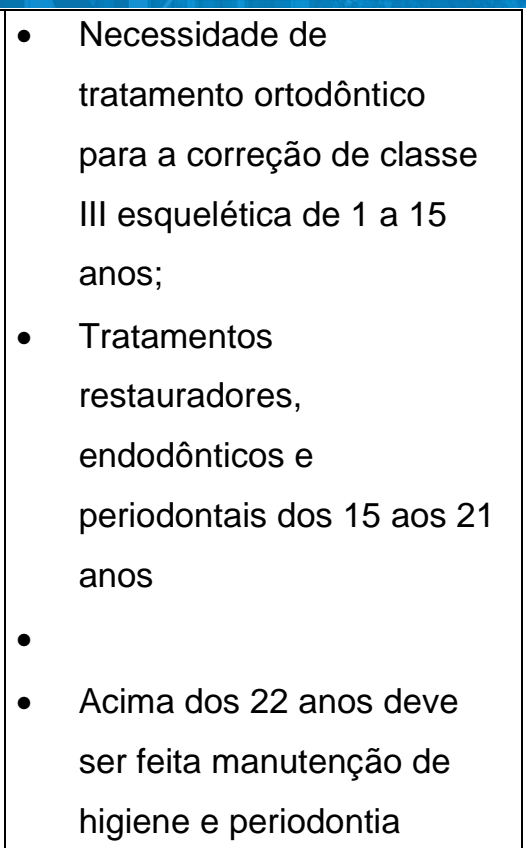 \\
\hline $\begin{array}{l}\text { ROMA et al., } \\
2021\end{array}$ & $\begin{array}{l}\text { Uma paciente de } \\
23 \text { anos }\end{array}$ & IA Hipocalcificado & $\begin{array}{l}\text { 1. Motivação do paciente } \\
\text { para o tratamento e } \\
\text { manutenção da higiene oral; } \\
\text { 2. Tratamentos } \\
\text { endodônticos dos dentes } 37 \text {, } \\
47,47,16,26 \text {; } \\
\text { 3. Fornecimento de pônticos } \\
\text { temporários em todos os } \\
\text { dentes posteriores } \\
\text { para reconstrução da } \\
\text { dimensão vertical oclusal } \\
\text { perdida; } \\
\text { 4. Teste de próteses parciais } \\
\text { fixas e, } \\
5 . \text { Acompanhamento } \\
\text { periódico em intervalos de } 1 \\
\text { e } 2 \text { anos seguidos pelo }\end{array}$ \\
\hline
\end{tabular}

1Acadêmica do Curso de Odontologia - UFN - paolams98@hotmail.com

${ }^{1}$ Acadêmica do Curso de Odontologia - UFN - frandiasodonto@gmail.com

2Mestre em Saúde Materno Infantil - UFN - cristiane.savian@ufn.edu.br

3Mestranda em Saúde Materno Infantil - UFN - candidabonadiman@ufn.edu.br

${ }^{4}$ Professora do Curso de Odontologia - UFN - lwbento@ufn.edu.br

${ }^{4}$ Professora do Curso de Odontologia - UFN - simonepippi@ufn.edu.br

${ }^{4}$ Professor do Curso de Odontologia - UFN - mauriciomezomo@gmail.com

5Orientadora - Professora do Curso de Odontologia - UFN — biancazsantos@ufn.edu.br 


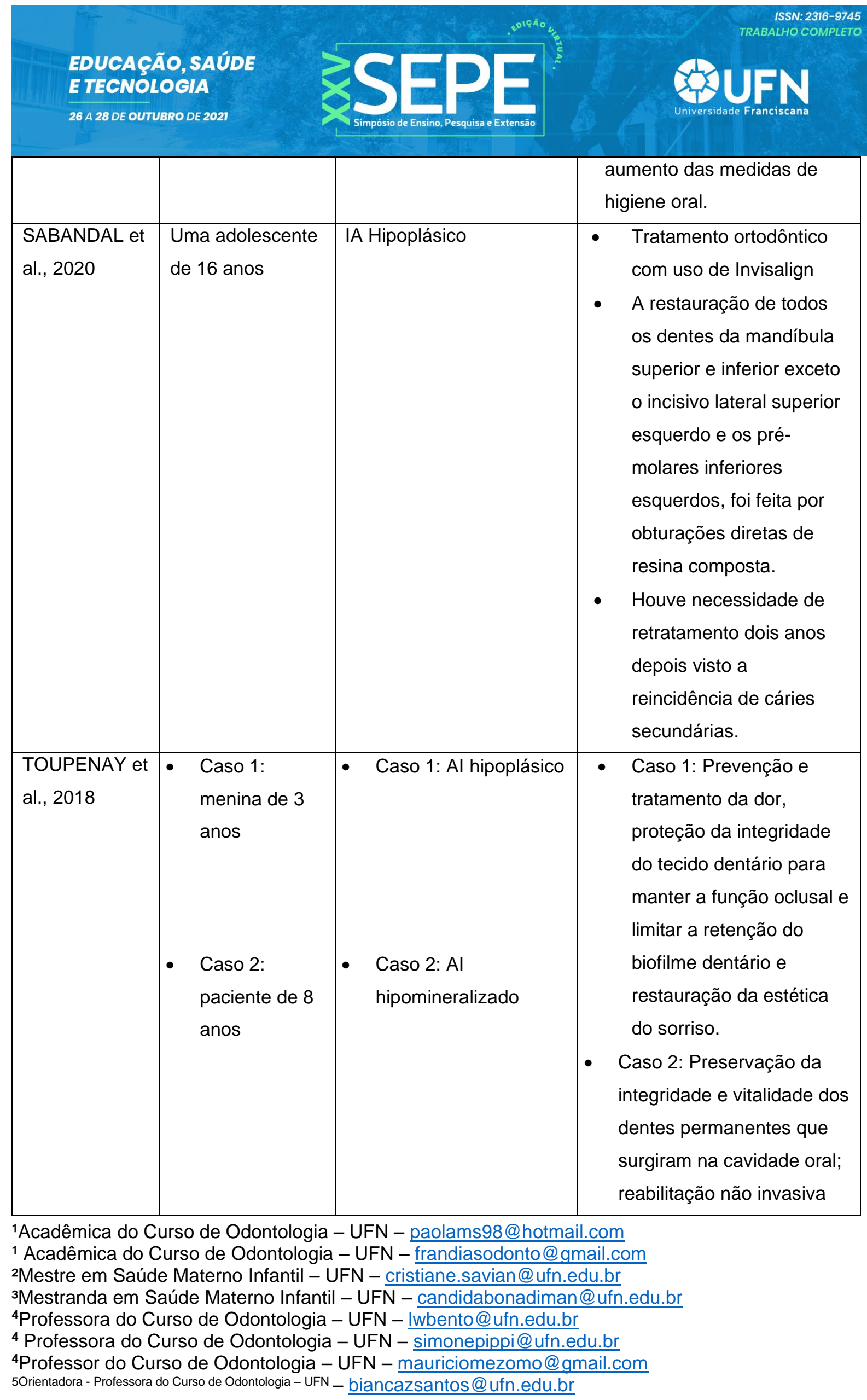




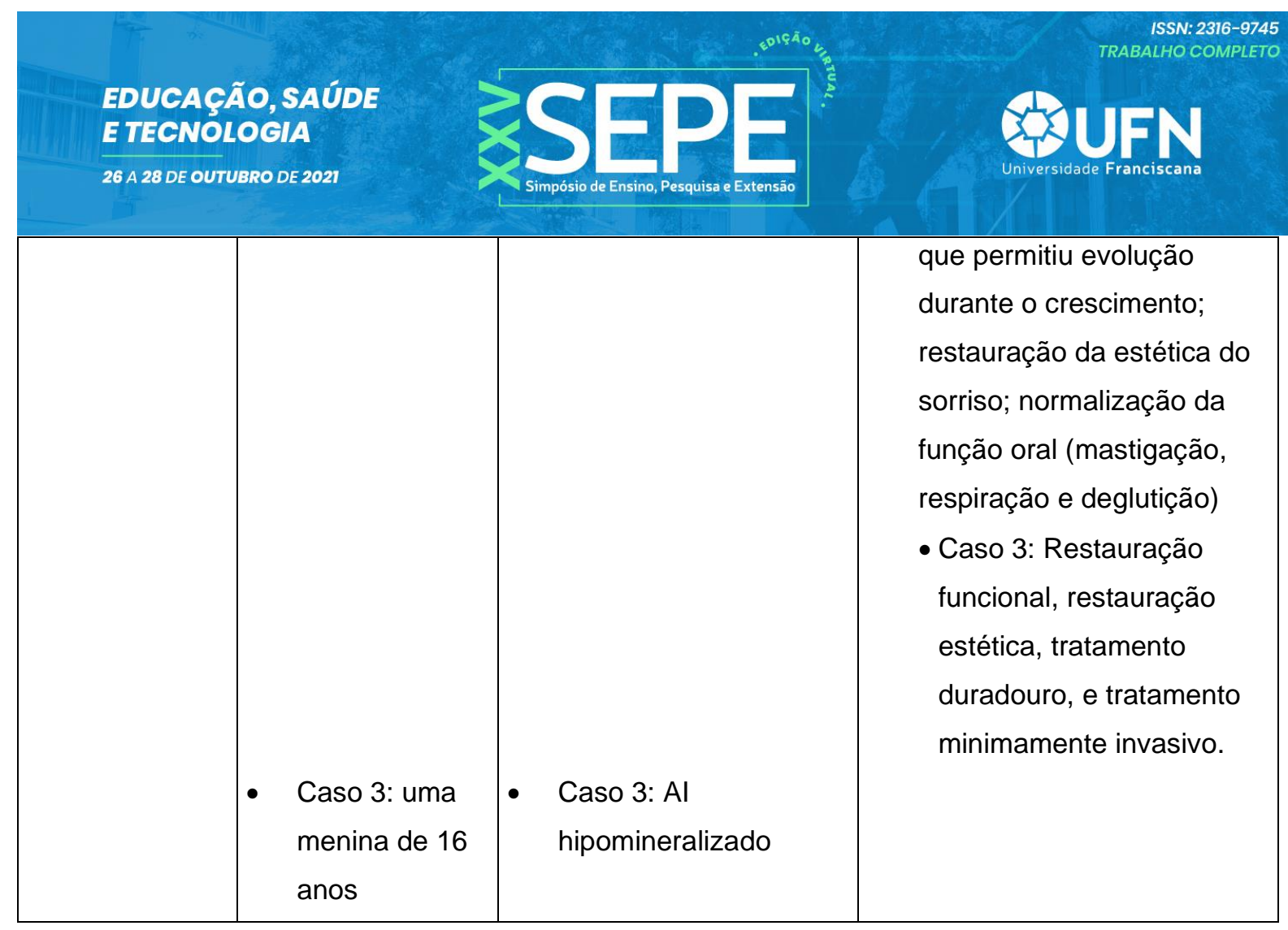

\section{CONCLUSÃO}

A amelogênese imperfeita é uma condição genética, cujas características clínicas variam de paciente para paciente, tendo uma grande necessidade de intervenção, principalmente estética. A má formação do esmalte causa lascamento do esmalte, dentina escurecida, e uma visibilidade estética desfavorável, o que pode causar baixa autoestima, doenças bucais e hipersensibilidade dentinária. Sendo assim, torna-se imprescindível a evolução de tratamentos não invasivos para a readequação bucal desses pacientes.

\section{REFERÊNCIAS}

ADORNO-FARIAS, D. et al. Diversity of clinical, radiographic and genealogical findings in 41 families with amelogenesis imperfecta. Journal of Applied Oral Science, v. 27, n. e20180359, p. 1-11, 2019.

\footnotetext{
${ }^{1}$ Acadêmica do Curso de Odontologia - UFN - paolams98@hotmail.com

1 Acadêmica do Curso de Odontologia - UFN - frandiasodonto@gmail.com

2Mestre em Saúde Materno Infantil - UFN - cristiane.savian@ufn.edu.br

3Mestranda em Saúde Materno Infantil - UFN - candidabonadiman@ufn.edu.br

${ }^{4}$ Professora do Curso de Odontologia - UFN - Iwbento@ufn.edu.br

${ }^{4}$ Professora do Curso de Odontologia - UFN - simonepippi@ufn.edu.br

4Professor do Curso de Odontologia - UFN - mauriciomezomo@gmail.com

5Orientadora - Professora do Curso de Odontologia - UFN _ biancazsantos@ufn.edu.br
} 
ALDRED, MJ. et al. Amelogenesis imperfecta: a classification and catalogue for the 21st century. Oral Diseases., v. 9, n.1, p.19- 23, 2003.

CRAWFORD, PJ. et al. Amelogenesis imperfecta. Orphanet Journal of Rare diseases, p. 2-17, 2007.

GOKCE, K. et al. Restoring function and esthetics in a patient with amelogenesis Imperfecta: a case report. The journal of contemporary dental practice, v. 8, n. 4, p. 95-101, 2007.

KIM, YJ. et al. A novel AMELX mutation causes hypoplastic amelogenesis imperfecta. Archives of oral biology, v. 76, n.1, p.61-65, 2017.

NEVILLE, B.W. et al. Anomalias dos dentes. In: NEVILLE; Patologia oral e maxillofacial, cap.2, p.49-92, 2004.

PHAROAH, Michael, J. Radiologia oral fundamentos e interpretações. 5 ed., p.342-343, 2004.

QUANDALLE, Camille et al. Gingival inflammation, enamel defects, and tooth sensitivity in children with amelogenesis imperfecta: a case-control study. Journal of Applied Oral Science [online], v. 28, n.1, 2020.

ORTIZ, L. et al. Management of Amelogenesis Imperfecta in Adolescent Patients: Clinical Report. Journal of prosthodontics: official journal of the American College of Prosthodontists, v. 28, n. 6, p. 607-612, 2019.

\footnotetext{
${ }^{1}$ Acadêmica do Curso de Odontologia - UFN - paolams98@hotmail.com

1 Acadêmica do Curso de Odontologia - UFN - frandiasodonto@gmail.com

2Mestre em Saúde Materno Infantil - UFN - cristiane.savian@ufn.edu.br

3Mestranda em Saúde Materno Infantil - UFN - candidabonadiman@ufn.edu.br

${ }^{4}$ Professora do Curso de Odontologia - UFN - Iwbento@ufn.edu.br

${ }^{4}$ Professora do Curso de Odontologia - UFN - simonepippi@ufn.edu.br

${ }^{4}$ Professor do Curso de Odontologia - UFN - mauriciomezomo@gmail.com

5Orientadora - Professora do Curso de Odontologia-UFN_biancazsantos@ufn.edu.br
} 
ROMA, M., et al. Management guidelines for amelogenesis imperfecta: a case report and review of the literature. Journal Med. Case Reports, v.15, n.1, p. 67, 2021.

SABANDAL, M.M.I., et al. Restorative treatment in a case of amelogenesis imperfecta and 9-year follow-up: a case report. Head Face Med., v.16, n.1, p. 28, 2020.

SANTOS, M.C.L.G, et al. The genetics of amelogenesis imperfecta: A review of literature. Journal of Applied Oral Science [online], v. 13, n. 1, p.212-215, 2005.

TOUPENAY, S., et al. Amelogenesis imperfecta: therapeutic strategy from primary to permanent dentition across case reports. BMC Oral Health, v. 18, n.1 p.108, 2018.

RAO, S., \& WITKOP, C. J. Inherited defects in tooth structure. Birth defects original article series, v. 7 n.7, p. 153-184, 1971.

\footnotetext{
${ }^{1}$ Acadêmica do Curso de Odontologia - UFN - paolams98@hotmail.com ${ }_{1}^{1}$ Acadêmica do Curso de Odontologia - UFN - frandiasodonto@gmail.com 2Mestre em Saúde Materno Infantil - UFN - cristiane.savian@ufn.edu.br 3Mestranda em Saúde Materno Infantil - UFN - candidabonadiman@ufn.edu.br ${ }^{4}$ Professora do Curso de Odontologia - UFN - lwbento@ufn.edu.br ${ }^{4}$ Professora do Curso de Odontologia - UFN - simonepippi@ufn.edu.br

${ }^{4}$ Professor do Curso de Odontologia - UFN - mauriciomezomo@gmail.com 5Orientadora - Professora do Curso de Odontologia - UFN _ biancazsantos@ufn.edu.br
} 